\title{
Planning Imperatives for Sustainability of Qualitative Educational Enterprise in Nigeria: The Role of the Educational Planner
}

\author{
Mgbekem, S. J. A. (PhD) \\ Faculty of Education, University of Calabar, Calabar, Nigeria \\ Ntukidem, P. J. (PhD) \\ Faculty of Education, University of Calabar, Calabar, Nigeria \\ and \\ Etor, R. B. (Ph.D) \\ Faculty of Education, University of Calabar, Calabar, Nigeria
}

\begin{abstract}
Planning Education is a prerequisite for achieving gains in educational enterprise. This paper presents prescriptions, which planners should adopt as a frame-work to do effective planning and implementation of educational programmes in Nigeria. The paper discusses National aspirations, National challenges, resultoriented planning, imperatives for goal achievement, and levels of education in Nigeria. Important suggestions are presented as recommendations drawn from the write up.
\end{abstract}

\section{Introduction}

The Nigerian educational system has often been criticized for poor planning inherited from colonial masters (Thompson 1981). It has been condemned for being unable to meet the needs and aspirations of the country as a result of its non-functionality, irrelevant curriculum, unrelatedness of the learning experiences etc. (Ozigi \& Canhan, 1979:194). The education process has been found to be faulty, inadequate and inefficient for Nigerian purposes e.g. non-achievement of national goal of technological transformation. The big question is: How should education in Nigeria be planned, to meet the needs, and aspirations of the individual citizen and the needs of society, and ultimately achieve the country's 
aspirations for National Development? Answer to this question is the main thrust

of this paper with regards to the role of the educational planner.

\section{Rationale for Planning Education in Nigeria}

Like all other enterprising organizations in human affairs, education in Nigeria must be efficiently planned, and effectively implemented to achieve the objectives, goals and national aspirations of Nigeria. Education is one of the avenues through which national development could be achieved. Bosah (1991:157) holds this opinion and is shared by many authors in Education. The National policy on education (1998), rates education as the most important instrument of change'. Most world countries use education as an instrument to plan national development. The potency of education as a change agent, is manifested in its effect on socialization, the transmission of culture, acquisition of skills, knowledge and societal norms as well as inculcating moral values and attitudes (Bosah 1991:157). This explains why education should be properly planned and effectively implemented.

All modern nations and developing ones including Nigeria, have confidence in the rewarding benefits of education. This is why Educational planning has been defined by Bosah (1991:157) as the process of determining in advance what you want to do in the field of education, and how you are going to do it to achieve productive gains such as those enumerated in paragraph one above. The roles of the educational planner in a result-oriented planning, presenting prescriptions or imperatives in planning, that will result in achieving goals, and national aspirations in educational enterprise in Nigeria maybe examined under the following sub-headings:

i. National targets/aspirations

ii. Challenges and problems of Educational planning

iii. Result-oriented planning

iv. Planning imperatives for the achievement of goals in education

v. Areas to be covered in planning education

vi. Consideration for levels of education in Nigeria

\section{National Targets}

The planner has two targets to consider: firstly, the needs of the individual citizen (the learner) and the needs of the society. The needs of the individual citizen in the country are paramount when one is considering educational planning. When the individual citizen is properly educated, he/she becomes an asset to the country. With the acquired knowledge, skills, and creativity, he/she can contribute to the development of society and the nation. This explains why the individual citizen should be given education to the best of their abilities and potential. In planning education for Nigeria, due consideration must be given to the individual learner and the society (the Nigerian Nation) i.e. what you want it to be, is what will lead it to get there. 
Planning based on these two targets is imperative, if goals of education in Nigeria must be achieved.

Secondly, the nation (Nigeria) is another target for serious consideration when planning education. Nigeria is ambitious to attain national development to be counted among the developed countries of the world. Thus, when planning education for Nigeria, focus must be directed towards those things that have caused other countries e.g. U.S.A. to become developed and those things which can make Nigeria to become a developed country, given all the natural endowments and abundant human and material resources at its disposal. Education in Nigeria must be planned to harness these available resources to get Nigeria developed to join the club of developed nations of the world.

In planning education, consideration must be given to the need to wipe out illiteracy in Nigeria, help to improve the quality of life, and help to acquire the ability to reason wisely and constructively. Planning must give attention to the fragile nature of the Nigerian nation, by emphasizing national integration and national unity when planning education. Ozigi \& Canhan (1977) observed that, this is very necessary if the fragile nation (Nigeria) is to be kept united. Educational planning is diverse in scope, hence, the planner he has a lot of work to do, to plan education to suit the Nigerian culture and background, which were ignored by colonial educationists. Consequently, the planner is starting from a new slate. Thus, the planner is confronted with numerous challenges and problems as discussed below:

\section{Challenges/Problems of Educational Planning}

The educational planner is confronted with the following national challenges which he must contend with and take them into consideration when planning education for Nigeria. They include among others, the following:

1. Emerging times and emerging changes

Changing times come, and go; changes emerge and require planning to match. To live in the past or believe that colonial educational structures were best for Nigeria, is to lag behind and stagnate. Educational planning confronts new times, new problems, new ideas, new changes and new awareness and new answers to changes. The planner must be aware of this and act in accordingly when planning education for Nigeria.

\section{Consideration of the Duration of Production of Educational Personnel}

The educational planner is faced with the problem of planning for teachers of the right calibre (trained teachers) medical doctors, civil engineers, mathematicians, agriculturists etc. It takes several years to produce these calibre of personnel who are relevant for national development. There must be a provision of appropriate educational institutions to produce and provide these enumerated essential personnel in the right quantity and quality to harness the economy for national development. This is the responsibility of the planner to handle. Colonial masters ignored this provision; Nigerian planners should not ignore this essential target. 


\section{Consideration of Proper Allocation of the scarce Economic Resources}

The planner cannot plan using pebbles or counting sticks. His planning is based on allocation of scare resources - money and highly qualified trained minds. Educational expenditure competes with other sectors of the economy namely: health, social services, agriculture, commerce and industries and others, in the national budget. The planner must make room for certain educational programmes which are more urgent and curtail those deemed less urgent. This requires discreet action and tact, but with full explanation, in order not to hurt interests, politicians, individuals, groups or communities concerned in the programmes.

4. Consideration of the Nature of the Nigerian Society:

The educational planner has to contend with Nigerian society. The society is complex and heterogeneous. With literate and illiterate people, political, social, economic and ethnic interests confronting the planner. To achieve the national goals, there must be understanding. Understanding of the National goals, calls for a co-operative endevour for a common federal plan on education e.g. the 6-3-3-4 year educational system, (1977), was nationally oriented. It enhances the sense of unity and common purpose and stimulates acceptability but, when such a programme is sectional, and designed to benefit one area or region, it becomes unacceptable. Nomadic education in the north must be balanced with fishing-ports-education in the south to make both acceptable. Planning must be done to take care of the two interests.

\section{Consideration of Wastage Arising from Incompetency:}

The planner faces duplication of educational programmes and institutions. It is cost-saving to concentrate school of technology in a definite center, school of medicine in another, agriculture in another etc. It is not advantageous to duplicate schools and programmes. For example there are too many grammar schools in Nigeria, producing mostly, art-oriented personnel at the expense of science and technical personnel. The planner has to contend with this imbalance and tilt the balance to fifty-fifty level base.

\section{Result-oriented Planning: What the Educational Planner is Expected to do in Educational Planning for Nigeria}

The Nigerian educational planner is expected to embark on planning education for Nigeria in the following areas as advocated by Ezeocha (1991). Providing for intelligent set of goals with political, social, economic, health and moral orientation and other e.g.

- Political goals would emphasizes national integration, patriotism and selflessness giving priority to the nation first, before self. e.g. Nigeria first, before Tom.

Social goals would emphasize the mixing up of youths of Nigeria in sports and games and national youth service corps as is being practiced now. 
- $\quad$ Economic goals would emphasize the development of economic resources of Nigeria as products for economic development e.g. crude oil, solid minerals and agricultural products.

- Health goals would emphasize men sana incorporate sane. A healthy mind in a healthy body.

- Moral goals would emphasize ethnical practices to maintain a sane society.

- $\quad$ Providing for Manpower Development: Every educational planner must appreciate that, high level manpower is essential for economic development of a nation. It is therefore the duty of educational system. The production and provision of manpower for the classrooms must be adequate and appropriate i.e. the quantity must be adequate and the quality must be high and appropriate. Manpower/personnel required in education must be suitable to serve the purposes and requirements for the different categories and levels of education to provide high level manpower for all sectors of the nation's economy.

Creating room for information or data collection on available skills and manpower resources, wastage, unused surpluses of labour, untrained personnel, sources of external assistance/and, to education, traditional/cultural, religious barriers requiring modernization should be considered in educational planning to avoid hitches during implementation of the plans. Room must be created for weighing the relevance of alternatives e.g.:
a. Existing formal school programmes or another option
b. The new formal school programmes or any other programme
c. Sponsored programmes by industries or by the public
d. On-the-job training or skill acquisition training
e. Adult education programmes to wipe out illiteracy or compulsory education for all

f. Curricula - what type of curriculum is best suited for Nigeria.

The planner should provide for balancing between urgent/important and less urgent programmes. This requires making hard choices and assigning priorities to different levels of education making hard choices and considering them in sequential phases for implementation of the plan.

- The planner should plan for regular flow of ideas and make room for expansion as need arises and make allowances for alterations of planned programmes during reviews of the plans, as experienced during implementation.

- The planner should provide for frequent evaluation and systematic review to discover new problems and insert new goals into the planned programmes. 
- Sources of financial support needed for the stages and aspects of the plans must be indicated. A planner is usually asked: Did you provide for these enumerated criteria of planning? They (planners) must adequately provide for some of these criteria, if they cannot provide for all.

\section{Planning Imperatives for the Achievement Goals in Education}

The educational planner should avoid the following:

a. Quantity should not be taken for quality and vice versa, in view of so many things to be done in education, each has its own merit.

b. Both quality and quantity must be planned for. The planner should indicate what should be done first as against what should be done later. Priority attention should be given to the more urgent and important pressures. (Ezeocha 1991).

c. Wisdom in decision making about value judgement is necessary. Weigh the demands of the economy, the social well-being of individuals and political necessities and make a decision based on weight/pressure.

d. Educational planners are to be courageous and have the will to take bold decisions on educational matters instead of feeling timid or frightened about what is involved in the plan.

e. Educational planners should consider quantity and quality, as relevant equals and place them at par during planning and not to consider one more important than the other. To do this is to meet hitches during implementation.

f. Planners should plan education to suit national interests and regional/state and local interests by adapting the plans to suit local needs to serve as compliment to national needs.

\section{Areas to be covered in Planning Education}

Education has been recognized as a positive change agent. Nigeria has great faith and confidence in it to do 'miracle', for her as it has done in advanced countries of the world. When the planner undertakes planning, he should take into account of Nigerian cultural background, the economic, social, political and moral factors. These considerations are discussed below.

\section{The Nigerian Society}

Nigeria is made up of 150 nations or ethnic groups, but for convenience, it is now grouped into three major regional groupings: Hausa - Fulani in the north with minor ethnic groups e.g. the Gwaris in between them, with many traditional arts and crafts, songs and dances which make them unique as a rural society, Ibos in the east, Yoruba in the west. The planner must plan education to reflect Nigeria's cultural heritage. He has not started planning if 
he fails to include this essential aspect of planning. (Ezeocha, (1991) posits that "no educational policy of Nigeria ...can be complete, without giving full encouragement to our cultural heritage". Nigeria is now split into 6 geopolitical zones. Education planners must consider these zones.

\section{Consideration of the Nigerian Economy:}

The planner is compelled to study and get a good grip of Nigerian economy to enable him balance is planning job. Nigeria depends on oil economy and agricultural products as secondary income earner. Both oil and agriculture yield revenue for her economic sustenance and survival. With revenue from oil and agriculture, Nigeria is investing and embarking on industrialization (technological turn around). The educational planner should plan education which is tilted toward technological transformation, planning should be done by preparing young Nigerians to handle technical aspects of the modernizing economy instead of employing expatriates to work for Nigeria at very high pay.

\section{Political Consideration}

Planners of education should regard political consideration as imperative because Nigeria is regarded as an artificial creations as a result of amalgamation in 1914. To cement the ties between ethnic groups, education must serve as the factor of integration of the several ethnic groups. That apart, the contradictions, ambiguities and lack of uniformity in the educational systems brought about by missionary bodies in 1850 s should be removed to ensure an even uniform and orderly development of the country. Uniformity in educational system is the answer to orderly development of the country. States which are still educationally disadvantaged should be provided for in planning to catch up fast with the educationally advantaged states through enlightenment campaigns, free education, legislation against early marriage, prevention of dropout of school etc. Although instability in Nigerian political history has affected, the work of planners, through change in government, yet, with the new political structure of democracy, replacing military regimes in Nigeria 9May 29, 1999), there is hope for educational planners in Nigeria to engage on enduring educational planning for Nigeria.

\section{Consideration of Culture: Language}

English is a foreign language used in Nigeria. To emphasize independence in Nigeria, the teaching of indigenous languages is emphasized. It is impossible to reflect 150 languages in the syllabus as languages of learning in schools. It is therefore sound to restrict the learning of indigenous languages to three: Hausa, Yoruba and Ibo. In planning for language education, three of these languages should be made compulsory but studying at least one of them or all three in schools in addition to English is emphasized.

\section{Religious Consideration}

The planner has to consider religious and moral education as important prescription to build an ethnical and moral society. The planner should plan education to reflect this subject 'to produce an educated person of sound and religious background' Ezeocha (1991:139). 


\section{Consideration of the Levels of Education in Nigeria}

The educational planner plans the following levels of education in Nigeria.

i. Pre-Primary Education: This is education for children of $3-5$ years of age.

ii. Primary Education: This education is given to children of $6-11$ years' old. It is free and universal.

iii. Secondary Education: This education is given to children who have completed primary school. It prepares children to enter university or work for useful living.

iv. Higher Education: This education includes Universities, Polytechnic, Colleges of Technology, Advanced Teacher - Training Colleges. It is for brilliant secondary school leavers who go in through Joint Admission and Matriculation Board Examination. In the Universities, teaching, research and publication are emphasized. The planner also plans for technical education, special education, teacher education, and adult education.

\section{Recommendations for a Result-oriented Planning of Education in Nigeria}

In making suggestions for improvement in educational planning, the following recommendations are proposed:

1. Planning - change is the emphasis. During missionary and colonial educational system, note learning (memory work was emphasized). A child was forced to learn all subjects of the school curriculum, whether it fits his intellectual capacities or not. This paper emphasizes change as a remedy for improvement in planning. The child should learn subjects, skills and programmes best suited to his abilities, and at the rate which they are capable. Although, core subjects are emphasized in education, there should be no attempt to enforce compulsory choice of subjects. Subjects should be chosen based on the changing times, considering the arrival of computer technology and automation (press button technique) into educational system.

2. Funding of education, should be handled by the Federal Government throughout the country because education is a single instrument to change Nigeria technologically. That is why education should be funded by Federal Government and make sufficient budgetary allocation to educational planning to ease planning, which results in achieving educational objectives and national goals.

3. Professional personnel in education should be placed in National planning board to advise national planners on the best way education should be planned to yield dividends for the country in terms of achieving national goals and development.

4. Refresher courses should be regularly mounted to update planner's technical skills on planning. 
5. Institutions which train teachers should incorporate planning programmes as electives to equip teachers with the skill of educational planning. This will in turn improve planning education in schools.

6. Administration of educational institutions should emphasizes conscious implementation of planned programmes. Schools administrators themselves should be planning agents and should train teachers to become planners. Planners of education should participate in the overall national planning. In fact, they should lead in national planning. They should give their expert advice during the exercise of development plans for the country.

\section{Conclusion}

Educational planning is undergoing changes, from colonial (1850s - 1950s0 to indigenous planning from 1970 - 2000 and so on. What is required of the planner is to base his planning on change, and the circumstances of the time, bearing in mind technological changes that influence society and its well being in the present age of automation.

Thus, every planning step taken by the planner should be guided and based on the changing circumstances of our time. The educational planner must be watchful and keep tract with trends and movement of the times and events, to enable him plan properly and keep abreast with times and circumstances.

The educational planner is aiming at quantitative and qualitative goals. If this is his avowed target, he must embark on short-term training, medium term planning, and long term planning, and watch their implementation successes, and review where necessary, so that when defects are revealed, they should be corrected without delay. Education being a change agent, it must be we planned and effectively implemented to reap its fruits.

\section{References}

Bosah, H. O. N. (1991). Challenges to Educational Planning in Nigeria in the 90's and beyond in Uwazurike C. N. (Ed.), Educational Planning and National Development: A Nigerian Perspective. Akwa: Mekslink Publishers, Nigeria.

Ezeocha, P. A. (1991). The need for a comprehensive National Plan for Education in Nigeria in Uwazurike C. N. (Ed.), Educational planning and National Development: A Nigerian Perspective. Akwa: Mekslink Publishers, Nig.

Federal Republic of Nigeria (1998). National Policy of Education. Lagos: Government Printers.

Ndu, Alice (1991). Educational Planning and Human Resources Development in Uwazurike C. N. (Ed.), Educational planning and National Development: A Nigerian Perspective. Akwa: Mekslink Publishers, Nigeria.

Ozigi, Albert and Canham Peter (1979). An Introduction of the Foundations of Education: London. Macmillan. 